\title{
Organization of change agents during care process redesign in Swedish health care
}

\author{
Anna Williamsson ${ }^{* 1}$, Andrea Eriksson ${ }^{1}$, Lotta Dellve ${ }^{1,2}$ \\ ${ }^{1}$ School of Technology and Health, KTH-Royal Institute of Technology, Stockholm, Sweden \\ ${ }^{2}$ Faculty of Caring Science, Work Life and Social Welfare, University of Borås, Sweden
}

Received: January 14, 2016

Accepted: February 14, $2016 \quad$ Online Published: February 25, 2016

DOI: $10.5430 /$ jha.v5n 3 p20

URL: http://dx.doi.org/10.5430/jha.v5n3p20

\begin{abstract}
Background: Swedish health care organizations (HCOs) are changing using management concepts such as Lean, in attempts of improving efficiency, quality of care and work environment. Since there are pre-conditional challenges for operative managers to engage in change, HCOs tend to assign supportive functions such as change agents (CAs) to facilitate change. Research on the use of CAs in HCOs is sparse, thus the aim of this study explores role assignments and conditions of formally appointed CAs contributing to care process redesign.

Methods: A purposive sample of three Swedish hospitals initiating Lean-inspired care process redesign during 2010-2011 was done. In-depth interviews were held with fifty-one key functions during change. Focus group interviews were conducted with thirty-eight health care professionals. Data were analysed by content analysis.

Results: Top managers' goal was to have operative management responsible for change during care process redesign, with support from assigned CAs. Organizing of CAs varied concerning, e.g. their hierarchical positions, job descriptions and practices, and conditions to act as driving forces towards change. Being granted formal power, having earned legitimacy and credibility, clarity regarding roles and responsibilities in change; a good sense of timing and ability to build relationships and trust, were identified as beneficial for CAs to support change.

Conclusions: Role assignment and organizing of CAs varies. A position closer to the operative levels, formalized and clarified responsibilities, earned legitimacy and timing support adaptation and alignment of planned change, such as Lean-inspired care process redesign.
\end{abstract}

Key Words: Change agent, Lean health care, Hybrid management, Change leadership, Change management

\section{INTRODUCTION}

Swedish health care is facing an extensive and increasing need for organizational change based on budget deficits and demands for improving efficiency, quality of care, and the work environment. A majority of Swedish health care organizations (HCOs) are changing by redesigning care processes according to strategies inspired by the management concept Lean production (LP), described both as a philosophy and a set of tools aiming at reducing waste, working with continuous improvements and increasing production flow and customer value. ${ }^{[1,2]}$ As part of the strategies for change, many Swedish HCOs have appointed change agents (CAs) to support these change processes. As yet, there are few studies on how the support through the CAs is organized and what implications this can have for transforming change. This article contributes to further development of the research field

\footnotetext{
*Correspondence: Anna Williamsson; Email: anna.williamsson@sth.kth.se; Address: School of Technology and Health, KTH-Royal Institute of Technology, Alfred Nobels Allé 10, 14152 Huddinge, Sweden.
} 
on roles and functions of CAs in $\mathrm{HCOs}^{[3]}$ and focuses on the support by CAs during the initial phases of implementation of planned, incremental changes within HCOs. Specifically, the study focuses on the organizing of and conditions for CAs supporting change according to care process redesign.

\subsection{Background}

Managers at operative levels are responsible for the implementation, adaptation and translation of top management's decisions in the daily service production. However, a recent study of change management during care process redesign showed that health care managers struggle hard with these responsibilities and often lack knowledge of this kind of change management. ${ }^{[4]}$ Several studies have described the challenges of managing change in the health care sector, e.g. the existence of competing logics of managerialism and professionalism and resistance from strong groups of health care professionals towards change based on management concepts. ${ }^{[5-7]}$ A wide range of terminology is used to describe key functions or roles during change. ${ }^{[8]}$ In the change management literature, a key role for change is that of the "champion". The champion is described to be a regular member of management or staff, who is an experienced professional, committed to, for example, a chosen management concept, and eager to influence colleagues. ${ }^{[9,10]}$ The $\mathrm{CA}$ is described in the literature as a facilitator having the knowledge and the methodological skills to pave the way, and promote and be a driving force for organizational change, as well as support implementation, adaptation and alignment of, for example, care process redesign following a chosen management concept..$^{[8,9,11-13]}$ Further, a literature review by McCormack and co-authors ${ }^{[8]}$ emphasizes that the CA's characteristics (such as establishing respect and credibility, being a positive role model, and engaging in reflective practice) are key features and need to fit the context and culture of the organization undergoing change. This study focuses on CAs as internal consultants that are formally appointed to reinforce change management, by supporting operative managers in their role during implementation of care process redesign. "Operative level" in this study refers to the implementers at the lower hierarchical level - departments and units - where patients are being cared for by health care professionals. ${ }^{[12,14,15]}$ Operative managers are therefore first line managers supervising a single unit, and second line managers supervising several first line managers at a department consisting of several units. "Strategic level" in this study is the sponsors at the upper hierarchical level where strategic, hospital-wide decisions are made by top management. ${ }^{[12,15]}$

There are many challenges to face during the implementation of organizational change. ${ }^{[3,16]}$ According to Todnem

Published by Sciedu Press
By's ${ }^{[3]}$ change management review (summarizing Kanter et al. 1992, Kotter 1996 and Luecke 2003), success in implementing transforming organizational changes is reached by considering certain transformational and important steps. The first steps focus on the initial implementation phase and include analysing needs in the organization, create a sense of urgency, develop a shared vision, and communicating that vision. ${ }^{[3]}$ The managerialism versus professionalism conflict during change in health care could be a sign that HCOs are failing in the first two abovementioned steps. Some of the resistance towards change within HCOs could be seen to derive from top management not engaging champions and professional key actors in the guiding coalition and therefore from not creating a vision that speaks to the operative levels. According to Cameron and Green ${ }^{[12]}$ this attunement of the vision means the values and preferred culture in the organization should be considered in the change process. Consequently, to engage health care professionals it is important that the top management more deeply take into account the health care professionals' views, understandings and motives. ${ }^{[7]}$ Operative managers who have been described as successful in managing change are so-called "hybrid managers" who can translate and bridge between managerialism and professionalism as well as between the strategic and operative levels. ${ }^{[17,18]}$ However, several studies show that operative managers' working conditions are such that time for bringing about change is limited, ${ }^{[19]}$ and they are in need of supportive functions such as CAs. ${ }^{[4]}$

Following steps concern empowerment to act on the vision and develop enabling structures to make sure that the members of the organization are able to adapt to the vision. ${ }^{[3,12]}$ Moon $^{[20]}$ describes how CAs need to have social awareness in order to achieve "common sense-making" among all stakeholders within the organization undergoing change. In this matter both alignment (i.e. shared understanding and orientation) and adaptability (i.e. tolerance for different views, and willingness to experiment and take risks) seem to be equally important. ${ }^{[12,21]}$ Damschroder and co-authors ${ }^{[9]}$ describe the polarities of implementing broad and consistent change across the organization (organizational adaptability) and implementing change in a more flexible way while considering the varying contexts within the organization (innovation adaptability). Holden ${ }^{[22]}$ argues for innovation adaptability when redesigning health care in line with LP. For successful implementation, he suggests to secure leadership by highlighting certain visible key actors in the implementation, as well as securing expertise over time by replacing CAs by appointed regular operative leaders or stakeholders, and allowing them to adapt the management concept to their local context. ${ }^{[22]}$ 
Consequently, operative managers are important for the adaptation and alignment of a management concept, but they need support in leading change processes during care process redesign. Additionally, health care professionals need support in communicating their ideas for change in order to engage and participate in organizational change. One way of meeting this need for initial support and while giving time for champions to stand out is to use formally appointed CAs who promote and support change at the operative level. ${ }^{[8,11,13]}$ However, there is a lack of knowledge concerning the circumstances and ways in which CAs contribute to change management at the operative level. ${ }^{[8]}$

\subsection{Aim}

This study explores role assignments and conditions of formally appointed CAs contributing to care process redesign in HCOs.

The exploration is pursued by responding the following research questions:

- What are the role assignments and organizing of CAs formally appointed to support lean-inspired care process redesign?

- What are the circumstances or the conditions under which the CA function can reach the objectives of supporting lean-inspired care process redesign?

\section{METHOD}

This study is part of a larger research program concerned with the implementation of LP in small to middle sized acute hospitals. The focus in the study is set on the role assignments, organization and conditions of formal CAs. Other studies within the research program cover complementary aspects of contextual factors that impact on the implementation of LP. For example, one study covers details on health care professionals' perceptions of LP, ${ }^{[23]}$ while another study covers the participating hospitals' motives for working according to LP. ${ }^{[24]}$ The current study contributes with knowledge of how, and under what contextual conditions, formally appointed CAs may support lean-inspired care process redesign.

\subsection{Study design}

A qualitative explorative approach was chosen to study the research questions at three Swedish hospitals. The study includes content analysis of $51 \mathrm{semi}$-structured individual interviews with key actors and nine focus group interviews with 38 health care professionals to gain a deeper understanding of the role assignments and conditions under which CAs are able to support care process redesign at HCOs.

\subsection{Study sample and data collection}

Three hospitals (HCOs) were purposively selected for this study, based on the inclusion criteria that the HCOs had adopted hospital-wide LP-inspired strategies when initiating care process redesign during 2010-2011. There were some similarities between the HCOs regarding the local context and the local conditions for redesign of care processes. The initiators for care process redesign shared the common goal that redesign and improvements of care processes should be driven by the operative management (i.e. the first and second line managers) at the HCOs and also the HCOs had formally appointed key support functions described as playing an important part in the planning for change. The purposive sample was also chosen in order to get a variation concerning organizing of change management and change management strategies at the participating HCOs. The selected HCOs had formally appointed support functions either for a short duration during the initial phase (less than 2 years), or as an ongoing strategy during change. The support functions in hospital A (HCO A) and hospital C (HCO C) had the same names but another name in hospital B (HCO B). In this study we address them all as CAs. To ease the comparison between the HCOs, each HCO participated with 3-5 units with the inclusion criteria of sharing the same flow of patients. These were mainly emergency, medical, surgical and intensive care units.

\subsubsection{Interviews}

First we interviewed the top management responsible for initiating the change management model at each $\mathrm{HCO}$. At $\mathrm{HCO}$ $\mathrm{A}$ and $\mathrm{HCO} \mathrm{B}$, these were the hospital managers and development managers. At $\mathrm{HCO} \mathrm{C}$, the county council manager, the county council development manager and the county council health care manager were interviewed first as initiators of the change management model, followed by the hospital manager and the hospital development manager. The interviews with the top management were conducted to investigate the chosen change management model, and the goals and strategies for the respective HCO. The interviews covered the following topics: the HCO's motives and strategies for change, key functions and resources during change, decision making during change, challenges of and opportunities during change, and the HCO's previous experience of change work.

To further understand how the strategies were implemented and operationalized, interviews were conducted with operative management, i.e. first and second line managers. A strategic sampling of operative management was made from the emergency department or a department with a high patient flow from the emergency department. The managers of the selected departments were included (second line man- 
agers), as well as unit managers (first line managers) from one or two units per each included department. From this selection those first and second line managers who gave their consent to take part in the study were interviewed. The interviewed operative managers from HCO A were first and second line managers from the following departments: emergency, intensive care, surgical care and medical care. The operative managers included at $\mathrm{HCO} \mathrm{B}$ were first and second line managers from: emergency, medical care (one medical care unit and one medical intensive care unit) and surgical care (one surgical care unit and one surgical intensive care unit). And finally, the operative managers included at $\mathrm{HCO}$ $\mathrm{C}$ were first and second line managers from: emergency and medical care (one medical intensive care unit and one acute neuro-care unit). At two units, two second line managers or two first line managers shared responsibility of managing and therefore both were interviewed. The interviews covered most of the interview topics also used in the top management interviews but were more focused on the operative work with care process redesign, such as: the change drive at the hospital unit; the manager's perception of support from key functions during change, communication and decision making; and health care professionals' engagement and participation.

The CAs, who had been pointed out by the top managers as having key functions during change and who had been assigned to work with the selected units, were interviewed next. At HCO C where the CAs were appointed to and working throughout the whole county council, all CAs assigned at the time of this study were interviewed. The interviews with the CAs covered the following topics: the CA's background, job description, and responsibilities, own views on the chosen management model, perceived impact on and drive during change, collaboration with managers and health care professionals during change, and challenges and opportunities during change.

The interviews yielded the names and roles of a few other key actors, and we decided to conduct additional interviews that could deepen the understanding of the change drive within the HCOs. In-depth interviews were conducted with two to three additional key actors at each HCO, such as: a care developer, care process group member, logistician or influential senior physician. These interviewees had not been specifically tasked with, and were not specifically committed to, driving change according to the change management model in focus (LP). The interviews covered a mix of interview topics used both in the top management interviews and in the CA interviews. For an overview of interviewees from each HCO (see Table 1A).
Focus group interviews were conducted with health care professionals in order to gain a broader view of the operative change and the CAs' visibility and practice on the hospital unit. Since most LP initiatives in HCOs are introduced at the emergency department ${ }^{[22]}$ the focus group interviews were held at the emergency departments and interviewees were grouped according to profession: assistant nurses, registered nurses, and physicians (see Table 1). At HCO A and B, all three professional groups were interviewed. At $\mathrm{HCO} \mathrm{C}$, focus group interviews were conducted with assistant nurses and registered nurses. The focus group interviews covered the following topics: work content, LP-inspired change strategies affecting clinical work, participation in improvement work, and previous experiences of organizational change and improvement work.

All interviews were conducted by one or two of the authors. Interviews, conducted during 2012, took place at the HCOs and lasted 40 minutes -90 minutes. The interviews were voluntary and all interviewees signed a written consent. Notes were taken during the interviews. All interviews, except those with county council and hospital directors, were recorded.

\subsection{Qualitative content analysis}

An inductive approach was chosen owing to little previous research concerning the study's focus: the use of CAs within HCOs undergoing change. ${ }^{[25,26]}$ To start the content analysis and gain a deep understanding of the manifest content, that is, of the interviewees' spoken words, the interviews were listened to and read through several times while simultaneously being analysed. Of the 51 in-depth interviews, 29 (the most informative interviews with CAs from each $\mathrm{HCO}$ and with all operative managers) were selected for full transcription while each of the remaining interviews was summarized and meaningful sections and quotes were selectively transcribed. Manifest codes were labelled and sorted regarding content. ${ }^{[27]}$ Summaries based on the manifest, contextual categories (see Table 2) were written for each HCO. During the process, patterns were identified iteratively and in constant comparison between raw data, notes and open codes. Content analysis of all interviews yielded manifest results concerning the assignment and organizational conditions for the CAs as well as the driving forces, facilitators and inhibitors during change, as perceived by managers and CAs.

Further analysis of all interviews resulted in latent codes, which are a condensation and interpretation of the meaning of what was said in the interviews. ${ }^{[27]}$ The latent content was organized into categories, highlighting beneficial conditions under which the CA could be the desired resource during change. Quotations from the 51 interviews were chosen to 
provide a picture of different CAs and of health care professionals' perceptions of the change and the CA resource on the operative levels.

Preliminary results (manifest coding, latent coding, and categories) were discussed continuously between the authors and in research seminars. The results were also validated in presentations and discussions with CA interviewees at respective HCO. For an overview of the content analysis (see Table 1B).

The research was approved by the ethics committee at Karolinska Institute in Stockholm, Sweden (ref: 2012/94$31 / 5)$.

Table 1. Number of interviewees and the contribution to the content analysis

A. Number of interviewees from the health care organizations (HCOs)

\begin{tabular}{|c|c|c|c|c|}
\hline & HCO A (n) & HCO B (n) & HCO C (n) & Total (n) \\
\hline Top managers (TMs) & 2 & 2 & 5 & 9 \\
\hline Operative managers (OMs) & 8 & 7 & 6 & 21 \\
\hline Change agents (CAs) & 4 & 4 & 6 & 14 \\
\hline Other key actors (KAs) & 2 & 3 & 2 & 7 \\
\hline Total & 16 & 16 & 19 & 51 \\
\hline $\begin{array}{l}\text { Focus groups with health care } \\
\text { professionals } \\
\text { (HCPs) ( } n \text { per interview) }\end{array}$ & $\begin{array}{l}\text { ass. nurse (3) } \\
\text { reg. nurse (4) } \\
\text { physician (two groups } 4+3 \text { ) }\end{array}$ & $\begin{array}{l}\text { ass. nurse (5) } \\
\text { reg. nurse (5) } \\
\text { physician (3) }\end{array}$ & $\begin{array}{l}\text { ass. nurse (4) } \\
\text { reg. nurse (7) }\end{array}$ & $\begin{array}{l}\text { ass. nurse (12) } \\
\text { reg. nurse (16) } \\
\text { physician (10) }\end{array}$ \\
\hline
\end{tabular}

B. The interviewees' contribution to the content analysis

\begin{tabular}{|c|c|c|}
\hline & Contribution to contextual, manifest categories & Contribution to latent categories, i.e. beneficial conditions \\
\hline Top managers (TMs) & $\begin{array}{l}\text { HCO’s overall strategy during change. Identifying } \\
\text { HCO’s CAs during care process redesign. CAs’ title, } \\
\text { start-up phase and job description. CAs’ task origin. }\end{array}$ & $\begin{array}{l}\text { Being granted formal power/earning legitimacy. Clarity in } \\
\text { roles and responsibilities during change. }\end{array}$ \\
\hline $\begin{array}{l}\text { Operative managers } \\
\text { (OMs) }\end{array}$ & $\begin{array}{l}\text { Change drive at operative level. OMs' support by KAs } \\
\text { other than CA*. CAs' assignments/tasks and OMs' } \\
\text { collaboration with CA**. }\end{array}$ & $\begin{array}{l}\text { Sense of timing, building relationships and trust }{ }^{* *} \text {. Being } \\
\text { granted formal power/earning legitimacy. Clarity in roles and } \\
\text { responsibilities during change. }\end{array}$ \\
\hline Change agents (CAs) & $\begin{array}{l}\text { HCO’s overall strategy during change. CAs' title, } \\
\text { start-up phase and job description. CAs' } \\
\text { assignments/tasks and responsibilities. CAs' } \\
\text { collaboration with TM, OM and HCP. Change drive at } \\
\text { operative levels. CAs' ability to provide support at } \\
\text { operative levels. Organization's request for support from } \\
\text { CA. }\end{array}$ & $\begin{array}{l}\text { Being granted formal power/earning legitimacy. Sense of } \\
\text { timing, building relationships and trust. Clarity in roles and } \\
\text { responsibilities during change. }\end{array}$ \\
\hline $\begin{array}{l}\text { Other key actors } \\
\text { (KAs) }\end{array}$ & $\begin{array}{l}\text { HCO’s overall strategy during change. Change drive at } \\
\text { operative levels. KAs’ ability to provide support at } \\
\text { operative levels. CAs' assignments/tasks and } \\
\text { responsibilities. KAs' collaboration with CA. }\end{array}$ & $\begin{array}{l}\text { Being granted formal power/earning legitimacy. Sense of } \\
\text { timing, building relationships and trust. Clarity in roles and } \\
\text { responsibilities during change. }\end{array}$ \\
\hline $\begin{array}{l}\text { Focus groups with } \\
\text { health care } \\
\text { professionals (HCPs) } \\
\text { (n per interview) }\end{array}$ & $\begin{array}{l}\text { HCPs' collaboration with CAs. HCPs' views on HCO’s } \\
\text { overall strategy during change. Communication between } \\
\text { hierarchical levels during change. Change drive at } \\
\text { operative levels. HCPs' request for support from CAs or } \\
\text { KAs. }\end{array}$ & $\begin{array}{l}\text { Being granted formal power/earning legitimacy. Sense of } \\
\text { timing, building relationships and trust. Clarity in roles and } \\
\text { responsibilities during change. }\end{array}$ \\
\hline
\end{tabular}

Note. Each interviewee validated data from other interviewees; ${ }^{*}=\mathrm{OMs}$ at $\mathrm{HCO}$ A did not contribute to this category; ${ }^{* *}=\mathrm{OMs}$ at $\mathrm{HCO} \mathrm{C}$ did not contribute to this category

\section{RESULTS}

The results are presented in two subsections. The first subsection summarizes the descriptive manifest categories, in relation to each studied HCO. The second subsection presents the three identified latent categories conceptualizing beneficial conditions for CAs supporting care process redesign.

\subsection{The assignment of and organizational conditions for CAs}

The CAs were placed at different levels in the HCO hierarchy in the different HCOs. Partly depending on their placement they differed in their ability to influence decisions concerning focus, how to lead, what to communicate, and how and where to communicate the management concept, and when to 
implement change. There were also differences between the HCOs concerning the CAs' responsibility for driving change, drawing up follow-up metrics, and communicating results during the change process. The CAs' placement within the HCO hierarchy also affected their closeness to the operative levels and the opportunity they had to take part in, and influence, everyday operative work (see Table 2).

There were similarities between HCO A and HCO B re- garding the CAs' placement and closeness to the practical realities of the operative levels and how their assignments evolved according to the CAs' personal conviction, competence, interests, cooperation with first and second line managers, and cooperation with other CAs within the same $\mathrm{HCO}$. At $\mathrm{HCO} \mathrm{C}$, the evolvement of the CAs' assignments, from being process leaders to being method supporters, was not a development affected by the CAs themselves, but a decision made at county council level.

Table 2. Descriptive results concerning the health care organizations (HCOs A, B and C) and their organization and assignment of respective $\mathrm{CAs}$

\begin{tabular}{|c|c|c|c|c|c|c|c|}
\hline & \multicolumn{7}{|c|}{ CONTEXTUAL MANIFEST CATEGORIES } \\
\hline & $\begin{array}{l}\text { HCOs' overall } \\
\text { strategy } \\
\text { during change }\end{array}$ & $\begin{array}{l}\text { CAs' title, } \\
\text { start-up phase } \\
\text { and job } \\
\text { description }\end{array}$ & $\begin{array}{l}\text { CAs' } \\
\text { operative } \\
\text { level/board } \\
\text { membership }\end{array}$ & CAs' recruitment & $\begin{array}{l}\text { CAs' } \\
\text { background/education }\end{array}$ & CAs' task origin & $\begin{array}{l}\text { CAs' } \\
\text { assignments/tasks }\end{array}$ \\
\hline HCO A & $\begin{array}{l}\text { Local CAs with } \\
\text { focus on } \\
\text { continuous } \\
\text { improvements } \\
\text { at the operative } \\
\text { level. }\end{array}$ & $\begin{array}{l}\text { 2010: Improvement } \\
\text { leader. New } \\
\text { position with no } \\
\text { written job } \\
\text { description. }\end{array}$ & $\begin{array}{l}\text { Department } \\
\text { level/ } \\
\text { department } \\
\text { board }\end{array}$ & $\begin{array}{l}\text { Head-hunted } \\
\text { internally or } \\
\text { externally }\end{array}$ & $\begin{array}{l}\text { Registered nurses with } \\
\text { varying experience in } \\
\text { leadership and } \\
\text { organizational } \\
\text { development work. Some } \\
\text { educated in Lean } \\
\text { production (LP) in } 2010 .\end{array}$ & $\begin{array}{l}\text { One to two second and } \\
\text { first line managers } \\
\text { within the department } \\
\text { (number of units } \\
\text { depending on department } \\
\text { size). Some of them } \\
\text { working partly with top } \\
\text { management. }\end{array}$ & $\begin{array}{l}\text { Coach, project } \\
\text { leader, method } \\
\text { supporter, problem } \\
\text { solver, idea } \\
\text { generator. Tasks } \\
\text { differ between } \\
\text { departments. }\end{array}$ \\
\hline HCO B & $\begin{array}{l}\text { Introduction/ } \\
\text { education of } \\
\text { managers to/in } \\
\text { LP and } \\
\text { initiating } \\
\text { change at } \\
\text { several levels in } \\
\text { the HCO }\end{array}$ & $\begin{array}{l}\text { 2012: Development } \\
\text { controller. Partly } \\
\text { new position with } \\
\text { tasks added to } \\
\text { already existing job } \\
\text { description. }\end{array}$ & $\begin{array}{l}\text { Department } \\
\text { level/ } \\
\text { department } \\
\text { board }\end{array}$ & $\begin{array}{l}\text { 2010: Internal } \\
\text { recruitment. Own } \\
\text { application for new } \\
\text { position when } \\
\text { assistant department } \\
\text { manager function } \\
\text { ceased to exist. }\end{array}$ & $\begin{array}{l}\text { Health care professionals } \\
\text { and former managers with } \\
\text { experience of managing } \\
\text { within and outside the } \\
\text { HCO. Educated in process } \\
\text { development in } 2010 \text { and } \\
2012 \text {. }\end{array}$ & $\begin{array}{l}\text { One to two second and } \\
\text { first line managers } \\
\text { within the department } \\
\text { (number depending on } \\
\text { department size). Partly } \\
\text { working with top } \\
\text { management. }\end{array}$ & $\begin{array}{l}\text { Prepare statistics and } \\
\text { reports, method } \\
\text { supporter, assistant } \\
\text { department manager, } \\
\text { idea generator. } \\
\text { Method support in } \\
\text { overarching, } \\
\text { hospital-wide } \\
\text { processes. }\end{array}$ \\
\hline HCO C & $\begin{array}{l}\text { Central CAs } \\
\text { educated in LP, } \\
\text { supporting } \\
\text { entire county } \\
\text { council }\end{array}$ & $\begin{array}{l}\text { 2010: Improvement } \\
\text { leader. New } \\
\text { position, with no } \\
\text { written job } \\
\text { description. }\end{array}$ & $\begin{array}{l}\text { County council } \\
\text { level/ no board } \\
\text { membership }\end{array}$ & $\begin{array}{l}\text { Head-hunted } \\
\text { internally }\end{array}$ & $\begin{array}{l}\text { Health care professionals, } \\
\text { engineer and human } \\
\text { resources specialist. } \\
\text { Varying experience in } \\
\text { leadership, management } \\
\text { and development work. } \\
\text { Educated in Six Sigma } \\
\text { Black Belt in 2010. }\end{array}$ & $\begin{array}{l}\text { County council through } \\
\text { project groups working } \\
\text { with certain processes } \\
\text { within the county (not } \\
\text { exclusively the health } \\
\text { care sector). }\end{array}$ & $\begin{array}{l}\text { Process leader during } \\
\text { their Six Sigma } \\
\text { training and work } \\
\text { with pilot processes. } \\
\text { Education of staff } \\
\text { within process } \\
\text { groups. Method } \\
\text { supporter. }\end{array}$ \\
\hline
\end{tabular}

\subsubsection{Driving and inhibiting forces within the health care hierarchy during the change process}

The operative managers' and CAs' perceptions of the driving forces during change towards improved care processes differed between the HCOs and with regard to the conditions embedded in the CAs' functions and roles at the different HCOs.

All CAs at $H C O A$ more or less had the role of advocating LP at the department where they were appointed. Their main approach was to encourage health care professionals and operative managers within their department to suggest improvements concerning their work and working environment. The CAs put up visualizing tools ("LP whiteboards") and held regular LP meetings at the units, during which these suggestions were discussed. However, the CAs' views on how to approach managers and health care professionals at their respective department differed and so did the response they had across the departments. The change initiatives at HCO A originated from the CAs. The CAs were the driving forces motivating both the second line managers, and (largely) the first line managers and health care professionals Some second and first line managers were driving forces as well, and at some units there was a registered nurse or group of nurses specially assigned to drive certain projects, and sometimes these nurses had a certain part of their time set aside for change. One CA was assigned to two departments; one $\mathrm{CA}$ focused more on the first line managers than on the second line manager; and at one department the CA seemed to operate alone without the help or involvement of any op- 
erative managers. At one department where the second line manager was sceptical towards the management concept, there was a perception of resistance from the subordinate physicians. Since the CAs' assignments at HCO A were time-limited there was a worry especially among the first line managers concerning whether or not the change drive and accomplished improvements would sustain without the drive from the CAs (see Figure 1).

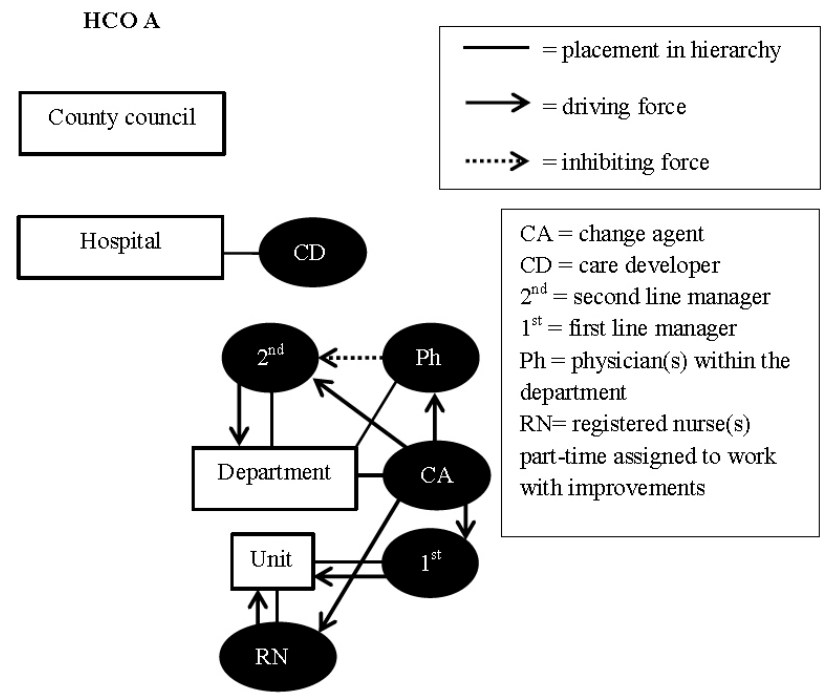

Figure 1. Key actors and their placement in $\mathrm{HCO} A$ Illustration of identified driving and inhibiting forces during the change process, in relation to the work practice of CAs.

At $H C O B$, the CAs were partly assigned to the $\mathrm{HCO}$ level and partly to the department level. They got their orders both from the hospital board and from the department board at the respective department where they were formally assigned. CAs were mainly method supporters. They supported their second line manager by providing metrics and evaluations, and the first line managers by, for example, providing visualization tools to show results or to be used during rounds. The initiatives and change process originated from the hospital management and went via the line of operative managers towards the units and, in some cases, towards groups of health care professionals working with certain projects. There was a driving and requesting approach between the $\mathrm{CA}$ and the second line manager, while the CA supported the first line managers in the department. Certain CAs within HCO B were sometimes given different hospital overarching assignments besides their department assignment. At one department the CA had been the former assistant second line manager, and still served as stand-in for the second line manager whenever this person was absent (see Figure 2).

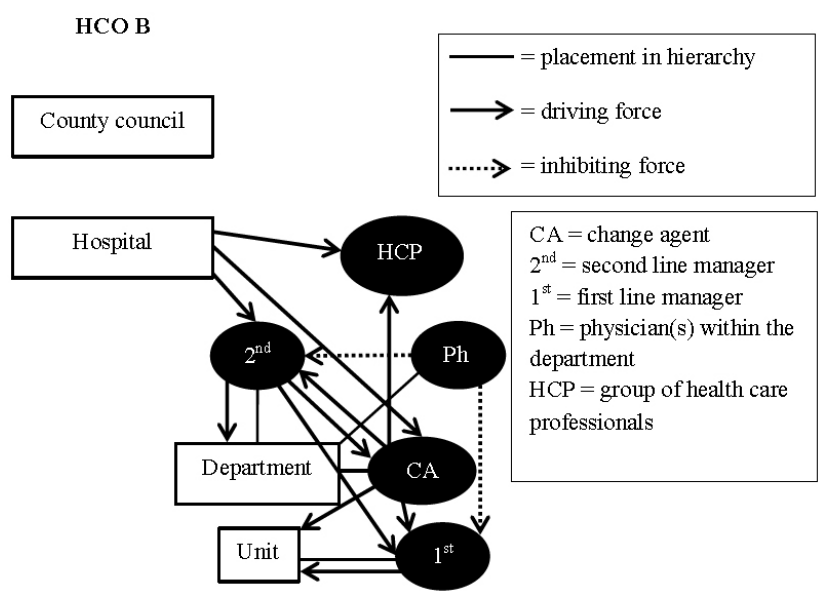

Figure 2. Key actors and their placement in HCO B Illustration of identified driving and inhibiting forces during the change process, in relation to the work practice of CAs.

At $\mathrm{HCO} C$, the CAs were assigned at county council level and their focus was on certain processes, a few at a time, chosen by the county council board, or identified by the hospital board and decided by the county council board. One or two CAs were part of a certain project group focusing on a certain care process. They gave support regarding the choice and use of methods and tools supporting the process work. The CAs had sparse contact with the operative levels. The responsibility for the progress of the process work in the process group, compliance on the operative levels, and follow-up and evaluation of the process work rested with the process owner, the operative managers and health care professionals within the process group. The driving forces were at different levels in the $\mathrm{HCO}$ hierarchy but originated from two levels: the county council board operating via the CAs; and the members of the process group, directed towards the departments involved in a certain care process. Occasionally, but rarely, the CAs supported units asking for method support when implementing the redesign of a certain care process according to the work of the process group. The driving forces at the department and unit levels more often came from a local improvement drive, that is, from specific champions. A local champion could be a second or first line manager with previous experience of working with LP. The methods and tools used by the local champions were partly in line with the LP-inspired management concept for care process redesign taken on by the county council board, but were run and developed at department level and were more or less supported by local care developers. The CAs at HCO C had initially (in 2010) been trained by an external consultant, and the same consultant was still coaching them over the phone whenever needed. The CAs' perceptions of the operative managers' and health care professionals' attitudes towards 
care process redesign differed and so did their perception of the attitudes affecting the change progress (see Figure 3).

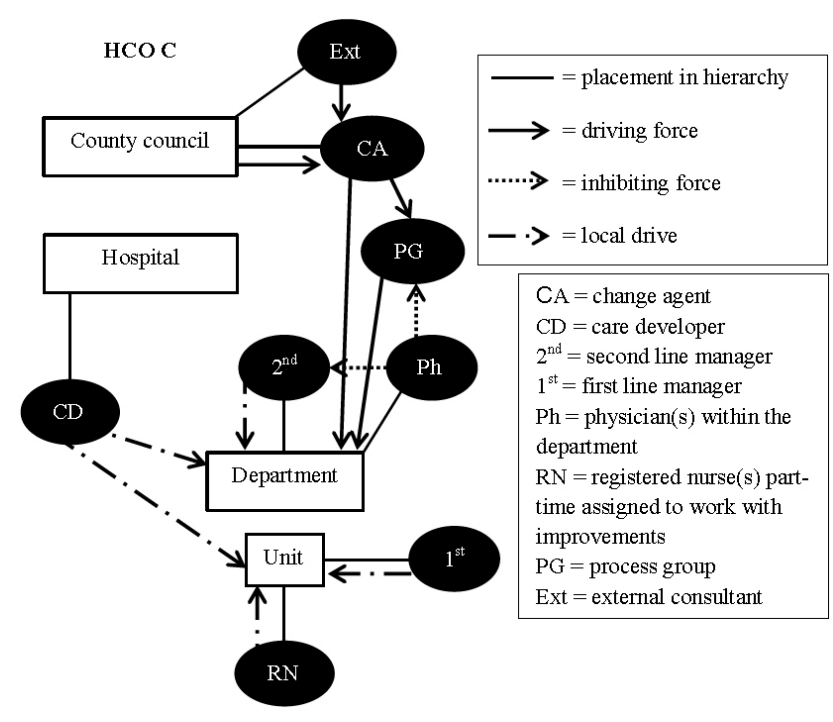

Figure 3. Key actors and their placement in $\mathrm{HCO} \mathrm{C}$ illustration of identified driving and inhibiting forces during the change process, in relation to the work practice of CAs.

Some resistance to change was seen from all health care professions but, as seen in Figures 1-3, in all HCOs the strongest inhibiting forces were perceived as originating from physicians and as being directed especially towards the second line managers to whom they were subordinate. At HCO C they were perceived as also directed towards the process group.

\subsection{Beneficial conditions for CAs to support care process redesign}

The HCOs' overall change strategies, the organizational placement of the CAs and their closeness to the operative levels influenced the CAs' ability to drive forward and contribute to the change progress during the initial phase of care process redesign. The identified beneficial conditions were considered to increase the CAs' ability to support change. The conditions are listed below and refer to quotations from in-depth interviews that are listed in Table 3.

\subsubsection{Being granted formal power from top management, while having earned legitimacy and credibility at the operative level}

- With formal power granted from top management, while having earned legitimacy at the operative levels, came the authority to have the desired impact during change. CAs who met these conditions and who were committed to the strategy of implementing change were considered more likely to have an impact and to effect change at the operative levels (quotation 1, see Table 3).

- Being subsidized by top management was described as necessary to get compliance and participation at the operative levels, and also having the power to influence prioritization of processes or projects facilitated a CA's work when driving forward (quotation 2 and 3, see Table 3).

- Legitimacy seemed to be best earned among one's own peers. The CAs who came from a nursing and managerial background themselves achieved legitimacy among these groups and managed to engage them in change. A successful CA needs to be able to engage professional groups other than his or her own and to recognize their needs (quotation 4 , see Table 3 ), and this involves a good sense of timing and the ability to build relationships and trust (see 3.2.2 below).

\subsubsection{Timing, building relationships and trust}

- Getting the timing right, that is, having the sensitivity to act and provide support at the right time, and having the ability to build relationships and trust, is important to understand and engage health care professionals and managers at the operative levels. A CA's closeness to the realities of the operative levels seems vital for how long it takes him or her to get to know the staff and him/ herself to become known and, furthermore, earn trust among health care professionals and managers (quotation 1, see Table 3).

- CAs who described themselves as being more contextsensitive in their analysis and resultant strategy also felt they had better opportunities to support the translation of their vision and strategy to the operative levels. They could then pick out the right tools from the toolbox that "fitted the target" and turn change work into a natural part of everyday work (quotation 5, see Table 3). Also, the more experienced CAs showed a more pragmatic side when driving change according to the change strategy (quotation 8 , see Table 3 ).

- Where the relations between a CA and the managers and health care professionals were more frequent and functional, the CA had better access to everyday issues. Furthermore, the more frequent and functional they were the easier it was to intervene at the right time and in the right way, and introduce change as a natural part of the managers' or health care professionals' work (quotation 1, 5, 6 and 7 , see Table 3).

- When, on the other hand, there was a geographic and hierarchical distance between the CAs and the opera- 
tive levels, the change drive depended more or less on the manager and health care professional representatives involved in a certain project, who needed to take the role of translators. And this could elicit engagement and participation among them (quotation 9 and 10, see Table 3).
- Where there was close collaboration between a CA and a manager, in combination with a joint training programme, both the manager and the CA described a shared understanding of the change strategy that increased the potential for joint responsibility for translation, adaptation and alignment (quotation 11, see Table 3).

Table 3. Examples of quotations supporting latent categories of beneficial conditions for CAs to support care process redesign

Examples of quotations

It takes some time to build trust and capital for them to know ... before they know what I can do and how I can

1 support them. But it feels like we're there now. [...] And then it is much more satisfying when you can work with the staff and not just the manager.

Many of the staff missed out on that event [an inspirational/educational LP evening event] because they were not

2 being paid for it. That was really important for the staff and we tried to tell this to the board, but they did not listen to us.

... but I have had some good support from the manager there. She has allowed me to take part in meetings or where possible - to release staff from their regular work to sit down and work towards improvements.

It is important to involve enthusiasts, informal leaders who are of equal importance and influential, [and] to

4 involve them [by asking], 'What do you think of these ideas, is this something to implement?' Or that you have some sort of discussion before you say, 'This is what we will do!' [...] - We don't think this dialogue even exists. ... it is very much a matter of instinctive feeling on our part. When we see that - oh, this is a bit weak, and we don't reach out ... - then we simply choose another tool to get them back on track, and then we can proceed.

I have tried to address a moderate number of problems. I can't take every problem that is put in the box. Instead I

6 have taken as much as the staff can manage time-wise, so they don't feel overwhelmed and think they can't manage. So I have tried to take each problem one at a time.

$7 \quad$ You need to be slick as a cat and responsive and very, very positive when they decide to act in a certain matter. It is the people on the floor that know how it should be solved. It is not always the managers and it is most certainly not me, but it is the physicians, the registered nurses and the assistant nurses that hold the answers. I can be there and give support, and by that I mean to ask questions, administer, plan and structure and to help implement improvement work.

I think an enthusiastic and driven co-worker could be just as good a process leader as a first line manager. It

9 depends on what authority you have at your home department and what acceptance you have among your colleagues to do these kinds of changes, to stand up and tell what direction we are heading in, and the others follow.

The tools or methods we used we simply chose because they felt adequate. We didn't want to take certain steps for the sake of the steps, but for the actual purpose.

Sure, we should work according to the job description, but in collaboration with my manager [second line manager] we try to find the tasks we feel are important and needed, so ... we are not that stringent in what is written in the job description .... As I said, needs arise differently depending on where we are and what situation we are facing at the department.

It is a bit odd - we have worked here since the end of August, and then in January we discovered that we have parallel tracks going on. And so we knocked on their door and talked to those people running the parallel track.

Now when I look back, I must say I experienced the instructions as very loose and fuzzy. We had an assignment to implement LP at the department, but that was pretty much it.

The biggest challenge is to get the majority of managers to stand up for changes they have approved. We can

14 support and hand out materials and such, and we could even be informants at the departments. But as long as the managers don't stand up for decisions they themselves have been part in making, our effort is wasted.

We have noticed how easy it is [for managers] to make decisions, but to comply with them and stand up to them and take them to the staff, that is definitely harder.

\section{Change agents}

Change agent at $\mathrm{HCO} \mathrm{B}$

Change agent at $\mathrm{HCO} \mathrm{A}$

Change agent at $\mathrm{HCO} \mathrm{A}$

Physician at HCO A

Change agent at $\mathrm{HCO} \mathrm{C}$

Change agent at $\mathrm{HCO} \mathrm{A}$

Change agent at $\mathrm{HCO} \mathrm{A}$

Change agent at HCO B

Change agent at $\mathrm{HCO} \mathrm{C}$

HCP/ Process group member at $\mathrm{HCO} \mathrm{C}$

Change agent at $\mathrm{HCO} \mathrm{B}$

Change agent at $\mathrm{HCO} \mathrm{C}$

Change agent at $\mathrm{HCO} \mathrm{A}$

Change agent at $\mathrm{HCO} \mathrm{C}$

Change agent at $\mathrm{HCO} \mathrm{C}$

\subsubsection{Clarity in roles and responsibilities across the organization}

- For the CAs to be able to work according to their assignments, there was a need for clarity regarding power, and the roles and responsibilities of all functions involved in change. Almost all interviewed CAs 
asked for clarity, which also included transparency in the organization and awareness of the responsibilities of assigned CAs (quotation 12 and 13, see Table $3)$. This was especially expressed in relation to operative managers' responsibilities in redesign of care processes (quotation 14 and 15, see Table 3).

- A written job description of the CA's work, including boundaries to their work, could decrease the risk of the CA feeling that his or her work is limitless and never ending (quotation 13, see Table 3). Simultaneously, CAs and operative managers expressed how the $\mathrm{CA}$ had to be able to adapt to fluctuations in the needs of the organization. Therefore the job description needed to be open to some degree (quotation 11, see Table 3).

\section{Discussion}

This study contributes to knowledge about the use of CAs during care process redesign. It explores role assignments of formally appointed CAs and potential critical success factors seen as beneficial conditions for CAs to support the intended change. The results revealed differences in how HCOs organize their CAs, from department-placed CAs working directly with staff as initiative advocates for LP or working closely with operative managers as method and metrics supporters, to central CAs serving an entire county as method supporters in selected care processes. Seen in the light of previous change management research, ${ }^{[17,18,21,22]}$ our results show that these differences give various opportunities for CAs to support alignment and change management at operative levels. According to Block's ${ }^{[14]}$ classification of CAs in the consulting process: (1) the expert, (2) the extra pair of hands, and (3) the collaborative role, the CAs in our study represent a mix of all three classifications. CAs placed close to the operative levels that enjoy legitimacy among health care professionals and operative managers have better chances of supporting alignment and have a greater impact on change drive and adaptation of the change strategy. CAs placed close to operative management also have increased possibilities to support change management in practice. These opportunities are enhanced by organizational clarity regarding roles, as well as the right timing for the provided support.

\subsection{Supporting alignment}

An improvement strategy that is inspired by an industrial concept such as LP needs to be adapted to the health care context when being communicated to health care professionals in order to be listened to in the first place, and accepted across the HCO in the long run. ${ }^{[6,7,22,28]}$

During change it is of great importance to achieve alignment Published by Sciedu Press across the $\mathrm{HCO}$ - that is, to achieve shared understanding and orientation, common values and priorities within the $\mathrm{HCO}^{[12,21]}$ - and to attain clarity concerning roles, responsibilities and the possibility of adapting the strategy to the local context. ${ }^{[22,29]}$ In our study, CAs with powers formally granted by a sponsor, i.e. top management, supported the creation of the vision of the HCO, and earning legitimacy among implementers, i.e. managers and health care professionals, gave the CAs a chance to support alignment in terms of engaging the operative levels to act on the vision. ${ }^{[3,12]}$

Part of the struggle the CAs in this study had in earning legitimacy and reaching out to the operative levels seemed to have to do with buying into the LP-inspired change management model across the organization. However, it is top management that holds the greatest responsibility both in communicating the vision and change strategy in a way that speaks to the members of the HCO, and in removing hindering constraints. Since the roles and the responsibilities of some of the CAs were unclear it is hard to tell whether the HCOs had a vision of care process redesign through organizational adaptability or through innovation adaptability. ${ }^{[9]}$ Was the CA just a messenger of the vision - the top management's extended arm towards the operative levels or was he or she intended to support the operative levels in implementing care process redesign in their own fashion ${ }^{[8]}$ ? When supporting alignment the CA not only needs to work on social awareness within the organization but also needs to be aware of the stakeholders' "common sense-making" of what is right for their organization - in this case, their HCO.$^{[9,12,20]}$ In cases where the CAs had a good sense of timing, and were able to build relationships and trust and secure formal powers from top management, there was an opportunity for innovation adaptability and re-creation of the vision according to the needs and wishes expressed at the operative levels.

The downside of innovation adaptability could be seen in CAs working without a common conviction or shared understanding of the vision. In such cases, their part in contributing to alignment within the organization is scattered. An educational programme that brings CAs and managers together could give them a common language and, as $\mathrm{Moon}^{[20]} \mathrm{de}-$ scribes it, a common sense about the change. In this way the alignment between their common sense and the change strategy could increase. With no common sense-making or shared understanding, CAs are left on their own to interpret the vision and change strategy to something aligned with their own beliefs and convictions about how to bring about change. This situation may help the CAs to build relations and reach out to the managers and professionals within the organization, but it will not contribute to alignment across 
the organization. ${ }^{[21]}$ With the beneficial conditions in place, however, the CAs could balance organizational adaptability and innovation adaptability and support alignment and thus bridge the gap between the strategic and operative levels.

\subsection{Supporting operative management in communicating and acting on the vision}

The implementation climate or culture within an HCO needs to mature to support, reward and claim engagement from stakeholders, in order for the $\mathrm{HCO}$ to be adaptable and learn from its failures and mistakes. ${ }^{[8,9,21]}$ In other words, members of the $\mathrm{HCO}$, the managers and health care professionals, need to be encouraged to be engaged, participate and be willing to share experiences during change. Previous research upholds the importance of health care professionals' engagement and collaboration in change. Implementing the LP concept especially depends on the collaboration and communication between units and departments if care process redesign is to be successful. ${ }^{[6,7,10,28]}$ The importance of securing expertise over time, by allowing operative managers or champions to replace CAs, is in line with the HCOs' common long-term goal of having operative management with change drive. ${ }^{[12,22]}$

Depending on the assignment and the intended use of the CAs, their placement within the hierarchy seems to be of varying importance. If CAs are placed geographically far from the operative levels and their assignment is limited to method support (i.e. not facilitation), earning legitimacy may not be as important since the translation and adaptation of the management concept is in a way forced on the operative management who can more easily earn legitimacy among peers and health care professionals. But then there is a catch-22 since, as research shows, health care managers, especially first line managers, are hybrid managers often drowning in practical work, with very limited time to work strategically. ${ }^{[19]}$ Managers need support in communicating the vision and empowering others to act on the vision. ${ }^{[12]}$ Accordingly CAs need to spend time and build relations at the operative levels to provide this support. ${ }^{[29]}$ A CA may have a great deal of experience in health care and managerial work, but has an even better chance of earning legitimacy if he or she is perceived as having formal power to re-create the vision in combination with being the spokesperson for the operative levels, and can thus increase engagement and participation in change. ${ }^{[8,29]}$

CAs need extensive experience in combination with time spent at the operative levels if their assignment includes engaging managers and health care professionals. This makes the pressure on the CA similar to the pressure experienced by first line managers, who are hybrid and virtually stuck between the strategic and the operative level. ${ }^{[17]}$ CAs support managers by relieving them of the pressure of being hybrid and taking this pressure upon themselves. Hybridity, though it may lead to increased bilateral pressure, does provide them with opportunities to have influence and make contributions.

Experiences from a UK LP implementation programme show that as the implementation progressed, so-called "enthusiast converters", professionals who within their original habitat had been exposed to the implementation and been among the key supporters of the programme, popped up and pushed the implementation further by "infecting" colleagues with their "LP spirit". ${ }^{[1]}$ In our study population the number of enthusiast converters as well as champions will likely increase and contribute to the alignment and adaptation of care process redesign at the three HCOs. In time it will ease the burden of the operative management and CAs carrying the initial change drive on their shoulders. But still, the intention of using CAs to facilitate and/or support change needs to be kept in mind. Therefore it is important to improve their conditions in order to grant them the possibility to contribute so that in time, enthusiast converters and champions will step forward and blossom.

\subsection{Methodological limitations}

During the interviews there were signs of potential champions working at different levels within the HCOs and they may already have had an impact on change. They represented the local driving forces at their department or unit and have been taken into consideration in the analysis. However, the focus in this study has been on the functions identified by each HCO's top management who initiated the LP-inspired change management model, as well as the conditions and assignments of these functions during change. Nevertheless the CAs were able to support these potential champions to align with the top management's LP strategy. Further, the county council at one of the included HCOs had a more central role in the implementation of the LP-inspired strategies. The other two HCOs were also affected by decisions taken at county council level, but were acting more independently in organizing and strategizing for change.

The conclusions in this study are drawn from the interviews from the three included HCOs and cannot be generalized to all health care contexts. However, the multiple data collection from different sources within the same $\mathrm{HCO}$, and also the validation of the results from each data source strengthens the results at each HCO. Therefore, the context-specific results described in the first result subsection can be considered valid and transferable to other hospital settings with 
similar contexts. Furthermore, the conceptualization in the second result subsection presents the shared central aspects of the issues found in the interviews and can therefore be transferred to broader $\mathrm{HCO}$ contexts.

\section{Conclusion}

The role assignments and organizing of formally appointed CAs varies, especially regarding organizational position. A position closer to the operative levels implies more opportunity to support adaptation and alignment of planned change. HCOs may be able to increase the beneficial conditions for CAs to support alignment and contribute to change management drive at operative levels by granting them formal power and by clarifying roles and responsibilities concerning change management across the organization. Also CAs' abil- ity to support alignment and change management drive seems to benefit from their sense of timing and ability to build relationships and trust and thus earned legitimacy among managers and health care professionals at the operative level.

\section{ACKNOWLEDgements}

This study is part of a larger health care research programme financed by the Swedish Council for Working Life and Social Research (FORTE) and AFA Insurance (an organization owned by Sweden's labour market parties). We would like to thank all the interviewees at the hospitals for dedicating their time and sharing their experiences with the research team.

\section{CONFlicts OF InTEREST Disclosure}

There are no financial or non-financial competing interests to declare.

\section{REFERENCES}

[1] Weimarsson H. Nio av tio sjukhus har gått över till "lean" [Nine out of ten hospitals have implemented Lean]. Läkartidningen. 2011; 108(39): 1915. PMid: 22111232. Available from: http://ww2.la kartidningen.se/store/articlepdf/1/17019/_1915.pdf

[2] Womack JP, Jones DT. Lean Thinking. London: Simon \& Schuster; 2003.

[3] Todnem By R. Organisational change management: A critical review. Journal of Change Management. 2005; 5(4): 369-380. http: //dx.doi.org/10.1080/14697010500359250

[4] Andreasson J, Eriksson A, Dellve L. Health care managers' views on and approaches to implementing models for improving care processes. Journal of nursing management (in press). 2015. http: //dx.doi.org/10.1111/jonm. 12303

[5] Choi S, Holmberg I, Löwstedt J, et al. Executive management in radical change-The case of the Karolinska University Hospital merger. Scandinavian Journal of Management. 2011; 27(1): 11-23. http://dx.doi.org/10.1016/j.scaman.2010.08.002

[6] de Souza LB, Pidd M. Exploring the barriers to lean health care implementation. Public Money \& Management. 2011; 31(1): 59-66. http://dx.doi.org/10.1080/09540962.2011.545548

[7] Lindgren Å, Bååthe F, Dellve L. Why risk professional fulfilment: a grounded theory of physician engagement in healthcare development. The International journal of health planning and management. 2013; 28(2): e138-e157. http://dx.doi.org/10.1002/hpm. 2142

[8] McCormack B, Rycroft-Malone J, DeCorby K, et al. A realist review of interventions and strategies to promote evidence-informed healthcare: a focus on change agency. Implementation Science. 2013; 8(1): 107. http://dx.doi.org/10.1186/1748-5908-8-107

[9] Damschroder LJ, Aron DC, Keith RE, et al. Fostering implementation of health services research findings into practice: a consolidated framework for advancing implementation science. Implementation Science. 2009; 4(1): 50. http://dx.doi.org/10.1186/1748-5 908-4-50

[10] Greenfield D, Nugus P, Travaglia J, et al. Factors that shape the development of interprofessional improvement initiatives in health organisations. BMJ quality \& safety. 2011; 20(4): 332-337. http: //dx.doi.org/10.1136/bmjqs.2010.044545

Published by Sciedu Press
[11] Esain A, Williams S, Massey L. Combining planned and emergent change in a healthcare lean transformation. Public Money and Management. 2008; 28(1): 21-26. http://dx.doi.org/10.1111/j.1 467-9302.2008.00614.x

[12] Cameron E, Green M. Making sense of change management: a complete guide to the models, tools and techniques of organizational change ( $3^{r d}$ edition). Kogan Page Limited. 2012.

[13] Massey L, Williams S. Implementing change: the perspective of NHS change agents. Leadership \& Organization Development Journal. 2006; 27(8): 667-681. http://dx.doi.org/10.1108/01437 730610709282

[14] Block P. Flawless consulting: A guide to getting your expertise used. John Wiley \& Sons. 2011.

[15] Mintzberg H. Power in and around organizations (Vol. 142). Englewood Cliffs, NJ: Prentice-Hall.

[16] Kotter JP. Leading change: Why transformation efforts fail. Harvard Business Review. 1995; 73(2): 59-67.

[17] Dellve L, Wikström E. Managing complex workplace stress in health care organizations: leaders' perceived legitimacy conflicts. Journal of Nursing Management. 2009; 17(8): 931-941. http: $/ / \mathrm{dx}$.doi.org/10.1111/j.1365-2834.2009.00996.x

[18] Wikström E, Dellve L. Contemporary leadership in healthcare organizations: fragmented or concurrent leadership. Journal of Health Organization and management. 2009; 23(4): 411-428. http://dx .doi.org/10.1108/14777260910979308

[19] Arman R, Dellve L, Wikström E, et al. What health care managers do: applying Mintzberg's structured observation method. Journal of Nursing Management. 2009; 17(6): 718-729. http://dx.doi.org $/ 10.1111 / \mathrm{j} .1365-2834.2009 .01016 . \mathrm{x}$

[20] Moon MY. Making sense of common sense for change management buy-in. Management Decision. 2009; 47(3): 518-532. http: //dx.doi.org/10.1108/00251740910946769

[21] Gill R. Change management-or change leadership? Journal of Change Management. 2002; 3(4): 307-318. http://dx.doi .org $/ 10.1080 / 714023845$

[22] Holden RJ. Lean thinking in emergency departments: a critical review. Annals of emergency medicine. 2011; 57(3): 265-278. http: //dx.doi.org/10.1016/j.annemergmed.2010.08.001 
[23] Holden RJ, Eriksson A, Andreasson J, et al. Healthcare workers' perceptions on lean: A context-sensitive, mixed method study in three Swedish hospitals. Applied Ergonomics. 2015; 47: 181-192. http://dx.doi.org/10.1016/j.apergo.2014.09.008

[24] Eriksson A, Holden RJ, Williamsson A, et al. A Case Study of three Swedish Hospitals' Strategies for Implementing Lean Production. Nordic Journal of Working Life Studies (in press). 2016.

[25] Elo S, Kyngäs H. The qualitative content analysis process. Journal of Advanced Nursing. 2008; 62(1): 107-115. http://dx.doi.org/1 $0.1111 / j .1365-2648.2007 .04569 . x$

[26] Williamson K. Research methods for students, academics and professionals: Information management and systems $\left(2^{\text {nd }}\right.$ ed). Wagga Wagga, Australia: Centre for Information Studies, Charles Sturt University; 2002. http://dx.doi.org/10.1533/9781780634203
[27] Graneheim UH, Lundman B. Qualitative content analysis in nursing research: concepts, procedures and measures to achieve trustworthiness. Nurse education today. 2004; 24(2): 105-112. http: //dx.doi.org/10.1016/j.nedt.2003.10.001

[28] Mazzocato P, Holden RJ, Brommels M, et al. How does lean work in emergency care? A case study of a lean-inspired intervention at the Astrid Lindgren Children's hospital, Stockholm, Sweden. BMC health services research. 2012;12(1): 28. http://dx.doi.org/1 $0.1186 / 1472-6963-12-28$

[29] Lacey MY. Internal consulting: Perspectives on the process of planned change. Journal of Organizational Change Management. 1995; 8(3): 75-84. http://dx.doi.org/10.1108/09534819510 090178 